$-305$

\title{
THEJOURNAL OF
}

$1069 \mathrm{C}$

CLINICAL

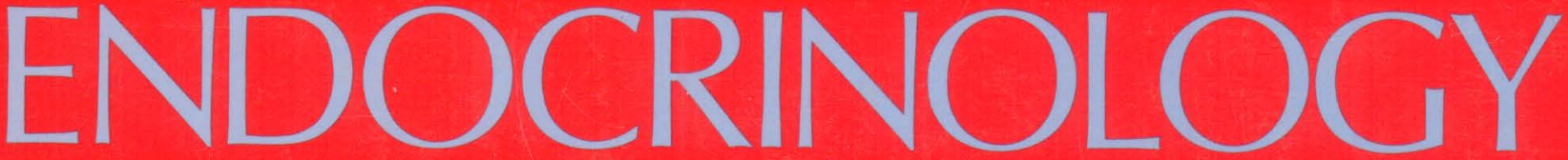

\& METABOLISM

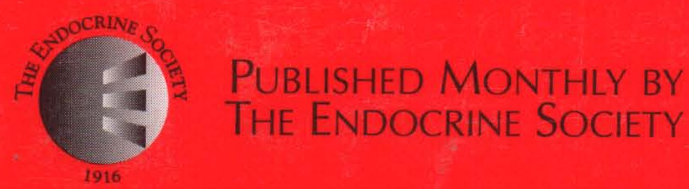

In this issue: Gonadotropin-releasing hormone receptor mRNA is

expressed in both cytotrophoblast and syncytiotrophoblast and exhibits changes paralleling the time course of hCG secretion during pregnancy.

(See page 580.)

Volume 80

- Number 2

February 1995 


\title{
Alterations in the Hypothalamic Paraventricular Nucleus and Its Oxytocin Neurons (Putative Satiety Cells) in Prader-Willi Syndrome: A Study of Five Cases*
}

\author{
D. F. SWAAB, J. S. PURBA, AND M. A. HOFMAN \\ Graduate School Neurosciences Amsterdam, Netherlands Institute for Brain Research, \\ Meibergdreef 33, 1105 AZ Amsterdam, The Netherlands
}

\begin{abstract}
Animal experiments have shown that the parvocellular oxytocin (OXT) neurons of the hypothalamic paraventricular nucleus (PVN) inhibit food intake. In the present study, the PVN and its OXT neurons have been investigated in an extreme human eating disorder, i.e. the Prader-Willi syndrome (PWS). PWS patients are characterized by gross obesity, insatiable hunger, hypotonia, hypogonadism, and mental retardation. The PVN of 5 PWS patients ( 2 males and 3 females), varying in age between $22-64 \mathrm{yr}$, and 27 controls (14 males and 13 females) without any primary neurological or psychiatric diseases was morphometrically investigated after conventional staining with thionine and immunocytochemical staining for OXT and vasopressin
\end{abstract}

(AVP). The thionine-stained volume of the PVN was $28 \%$ smaller in PWS patients $(P=0.028)$, and the total cell number was $38 \%$ lower $(P=0.009)$. The immunoreactivity for OXT and AVP was decreased in PWS patients, although the variability within the groups was high. A strong and highly significant decrease $(42 \% ; P=0.016)$ was found in the number of OXT-expressing neurons of the PWS patients. The volume of the PVN-containing OXT-expressing neurons decreased by $54 \%(P=0.028)$ in PWS. The number of AVP-expressing neurons in the PVN did not change significantly. The OXT neurons of the PVN seem to be good candidates for playing a physiological role in ingestive behavior as "satiety neurons" in the human hypothalamus. ( $J$ Clin Endocrinol Metab 80: 573-579, 1995)
A NIMAL experiments have shown that the parvocellular oxytocin (OXT) neurons of the hypothalamic paraventricular nucleus (PVN) are crucial for the regulation of food intake. These OXT neurons project to brain stem nuclei, e.g. the nucleus of the solitary tract and the dorsal motor nucleus of the nervus vagus (1-4). Small lesions in the PVN produce overeating and obesity (5), and stimulation of the medial parvocellular subdivision of the PVN elicits significant increases in gastric acid secretion (6). Central administration of OXT or OXT agonists inhibits food intake and gastric motility, whereas these effects are prevented by OXT receptor antagonists (6-9). The OXT neurons of the PVN thus seem to have an inhibitory effect on eating and body weight.

The present study deals with the question of whether a disorder of the PVN, in particular of its putative satiety neurons (the OXT neurons), may be the basis of the insatiable hunger and obesity in the most common type of human genetic obesity, i.e. the Prader-(Labhart)Willi syndrome (PWS) (10). Apart from gross obesity and problems during the birth process (11), this syndrome is characterized by diminished fetal motor activity, severe infant hypotonia, mental retardation, hypogonadism, and hypogenitalism (12). The last two features are of particular interest for our study, because OXT neurons are also thought to be crucial in various aspects of sexual behavior, i.e. sexual arousal, orgasm, sexual satiety, and other aspects of sociosexual interactions (13-17).

Received June 20, 1994. Revision received September 29, 1994. Accepted October 18, 1994.

Address requests for reprints to: Dr. D. F. Swaab, Graduate School Neurosciences Amsterdam, Netherlands Institute for Brain Research, Meibergdreef 33, 1105 AZ Amsterdam, The Netherlands.

* This work was supported by the Deventer-Maas Foundation.
The present study reveals a decrease in the size of the PVN and a strong and highly significant decrease in the number of OXT-expressing neurons in the PVN of PWS patients. OXT neurons in the human PVN are, therefore, good candidates for playing a physiological role in ingestive behavior as "satiety neurons."

\section{Materials and Methods}

The following five PWS cases were studied. Case 1: 44282 (Johns Hopkins Hospital, Baltimore, MD)

The patient was a 28 -yr-old male with a history of morbid obesity, hyperphagia, hypogonadism, and mental retardation. To control his weight, he underwent a gastric stapling procedure and gastrotomy. $\mathrm{He}$ was admitted to hospital for the evaluation of a personality disorder characterized by immature demanding and manipulative behavior, including self-mutilation. His IQ at that time was 77 . Some days before his death a noncontrast computed tomographic scan revealed hydrocephalus without focal lesions, ventricular calcifications, and slight prominence of the sulcal pattern. Despite aggressive management, the patient died of septic shock in dehydrated condition. There were no specific neuropathological features.

\section{Case 2: 43830 (Massachusetts General Hospital, Boston, MA)}

The patient was a 30 -yr-old woman who was the first child of a full-term gestation, weighing $3260 \mathrm{~g}$ at birth. In retrospect, the mother felt that the fetus had not been as active as her siblings in utero. The first couple of months she was very hypotonic and could not suck the breast or bottle effectively, so she was drip-fed. In adulthood, she suffered from massive obesity, gonadotropin deficiency [LH, 1.6 IU/L (normal, 3-120 $\mathrm{IU} / \mathrm{L}$ depending on the stage of the menstrual cycle); FSH, $0.5 \mathrm{IU} / \mathrm{L}$ (normal, 2-30 IU/L)], strabism, short distal extremities, and mental retardation (full scale IQ, 87; verbal IQ, 97; performance IQ, 76). Before her death she was frequently operated on because of her obesity, and she 
died of renal failure and generalized sepsis after one of these operations. The general pathology showed ovarian atrophy, with markedly underdeveloped secondary sexual characteristics. At autopsy, her length was $155 \mathrm{~cm}$, and her weight was $125.5 \mathrm{~kg}$. There were no special neuropathological features.

\section{Case 3: 91-252 (Onze Lieve Vrouwe Gasthuis, Amsterdam, The Netherlands)}

The patient was a 33-yr-old woman. In the few years after she had been diagnosed as a Prader-Willi patient, she was frequently admitted to various hospitals for congestive heart failure as a complication of her obesity. She died of pneumonia. At autopsy, she had severe dysmorphisms: a length of $150 \mathrm{~cm}$, an approximate weight of $160 \mathrm{~kg}$ with enormous fat accumulations in the abdomen and upper legs, narrow bifrontal diameter, hypopigmentation (hair, eyes, and skin), pectus excavatus, short extremities, atrophic ovaries, and hydrosalpinx of the left tube.

\section{Case 4: 93-056 (Cambridge Brain Bank Laboratory, Cambridge, United Kingdom)}

The patient was a 38-yr-old male with a history of hypotonia, obesity, small hands and feet, hypogonadism, an excessive sleeping pattern, and mental retardation. At the age of $3 \mathrm{yr}$, he was investigated for gross obesity ( $50 \%$ above average). No specific endocrine causes were found. From the age of 9-11 yr, he received anabolic steroids to boost growth and development. At the age of $15 \mathrm{yr}$, he underwent a bilateral orchidopexy and an IQ test (verbal score, 79; performance score, 70). His behavior became more and more problematic; he was caught stealing and, therefore, lost his job in an engineering firm. At that time, hospital assessment diagnosed a small, chubby, sexually underdeveloped man with stubborn, demanding, manipulative, and self-opinionated behavior. Some years later he was operated on for recurrent inguinal hernia. The patient died of ketoacidosis, known to occur with diabetes mellitus. Karyotyping did not provide any evidence of a deletion on chromosome 15.

\section{Case 5: 317-90 (Christian Mental Retardation Institute Hooge Burch, Zwammerdam, The Netherlands)}

The patient was a 64 -yr-old woman. From childhood she had been slow and inactive, with fits of anger. At the age of $34 \mathrm{yr}$, she was referred to a psychiatric clinic because of her behavioral problems. From the age of $40 \mathrm{yr}$, she was given low doses of neuroleptics. She had periods of somnolence, which became more frequent with age. She had many dysmorphisms: obesity (length, $165 \mathrm{~cm}$; weight, $84 \mathrm{~kg}$ ), small hands and feet, narrow bifrontal diameter, ptosis on the left side, scoliosis, and rotatory nystagmus. She was mentally retarded and had primary amenorrhea. She died of respiratory insufficiency. General pathology revealed a small uterus and small ovaries with a smooth surface (estrogen insufficiency).

The 5 PWS cases were compared to 5 age- and sex-matched controls that did not have any primary neurological or psychiatric diseases (see Table 1). In addition, the 5 PWS cases were compared to the entire group of 26 adult controls, i.e. 14 males and 12 females, whose OXT and arginine vasopressin (AVP) neurons had been determined by the same investigator (J.S.P.).

General pathology and neuropathology of the controls were performed at either the Free University in Amsterdam (W. Kamphorst) or the Academic Medical Center of the University of Amsterdam (D. Troost). The neuropathology of PWS patients was studied in several other places. The brains, obtained by autopsy after the necessary approval, were weighed and fixed in $4 \%$ formaldehyde and generally kept at room temperature for at least 1 month. Details on the age, postmortem delay, fixation time, and clinical diagnosis of the subjects are given in Table 1. The hypothalamic area, containing the PVN, was dissected, dehydrated in graded ethanol, and embedded in paraffin.

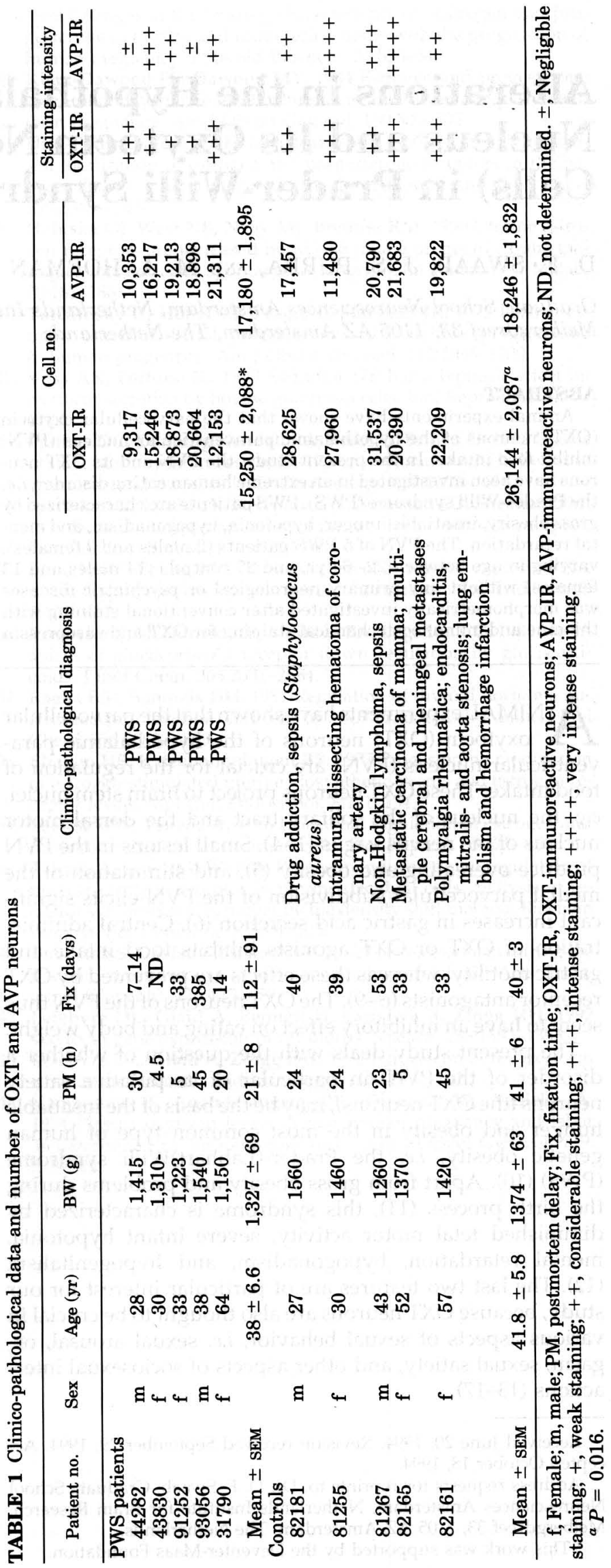




\section{Histology}

Serial 6- $\mu \mathrm{m}$ frontal sections were cut on a Leitz microtome (Leitz, Rockleigh, IL) and mounted on chrome-alum-coated object slides. Every 50th section was stained with thionine to locate the PVN before immunocytochemical staining.

\section{Immunocytochemistry}

Every 50th section was mounted on a chrome-alum-coated object slide, deparaffinized, hydrated, and stained with thionine $(0.1 \%$ thionine in acetate buffer, $\mathrm{pH} 4$ ).

Two series of sections taken at regular $300-\mu \mathrm{m}$ intervals throughout the region in which the PVN could be discerned in the thionine-stained material were stained immunocytochemically for AVP and OXT, respectively.

To remove cross-reactivity from the AVP (Truus, 18-9-85) and OXT antisera $(\mathrm{O}-1-\mathrm{V}, 4-4-75)$, the antisera were preabsorbed twice with OXTor AVP-glutaraldehyde-coupled Sepharose beads, respectively (18). The second incubation resulted in a complete removal of the cross-reactivity in the assay. In addition, cross-reactivity was checked in alternating $6-\mu \mathrm{m}$ sections of the PVN and revealed no cells staining with either antiserum (19). Mounted sections were hydrated and stained according to the following procedure: 1) incubation with purified AVP antiserum (1:300) or purified OXT antiserum (1:250) in $0.05 \mathrm{~mol} / \mathrm{L}$ Tris containing $0.9 \% \mathrm{NaCl}$ (TBS; $\mathrm{pH} 7.6$ ) with $0.5 \%$ Triton $\mathrm{X}-100$ (all incubations were performed at room temperature for $1 \mathrm{~h}$ and subsequently overnight at $4 \mathrm{C}$ in plastic boxes to prevent evaporation); 2 ) washing in TBS (twice, 10 min each time); 3) incubation with goat antirabbit immunoglobulin G serum (Betsie; $1: 100$ ) in TBS at room temperature for $30 \mathrm{~min} ; 4$ ) washing in TBS (twice, 10 min each time); 5 ) incubation with peroxidaseantiperoxidase (1:500) in TBS at room temperature for $30 \mathrm{~min} ; 6$ ) washing in TBS (twice, $10 \mathrm{~min}$ each time); 7) rinsing in $0.05 \mathrm{~mol} / \mathrm{L} / \mathrm{ris}-\mathrm{HCl}(\mathrm{pH}$

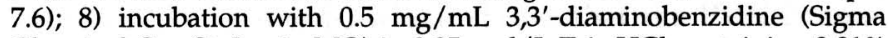
Chemical Co., St. Louis, MO) in $0.05 \mathrm{~mol} / \mathrm{L}$ Tris- $\mathrm{HCl}$ containing $0.01 \%$ $\mathrm{H}_{2} \mathrm{O}_{2}$ at room temperature for $10 \mathrm{~min} ; 9$ ) rinsing in Aquadest, followed by dehydration in graded ethanol at room temperature; and 10) coverslipping the sections with Entellan.

\section{Morphometry}

Cross-sectional areas of the PVN in thionine-, AVP-, and OXT-stained sections were measured with a Calcomp 2000 digitizer connected to an HP 9000/835 computer and with a Zeiss microscope (Zeiss, New York, NY) with PLAN 2.5x objective and PLAN 12.5x oculars. If the cross-sectional area of the PVN extended beyond the field of vision in a particular section, this area was measured stepwise using a quadrangular grid in one of the oculars as a reference. All sections containing three or more stained PVN neurons were included in the measurements. The PVN was measured at the right side of the brain, except when the nucleus was not completely present within the dissected tissue from that side.

The volume of the thionine, AVP, and OXT cell populations in the PVN was determined by integrating area measurements from the most rostral to the most caudal sections of each population (20).

Numerical total cell density (including neurons, glia, and endothelial cells) was estimated by counting all nuclear profiles per unit area, and AVP and OXT cell densities in the PVN were estimated by counting the total number of nuclear profiles of immunoreactive (IR) neurons per $U$ area. These procedures were followed by a discrete unfolding procedure (21) with the modification proposed by Cruz-Orive (22) and a correction for section thickness $(6 \mu \mathrm{m})$. For this purpose, nuclear profile areas were measured with the equipment described above, but with a PLAN $\times 40$ objective. To take local fluctuations in cell density into account, AVP and OXT cell nuclei in the PVN were sampled in a random systematic way (23) by measuring all nuclear profiles in every 200th section throughout the PVN (i.e. at $1200-\mu \mathrm{m}$ intervals), respectively every 300 th section (i.e. at $1800 \mu \mathrm{m})$, for total cell number in the thionine preparation. This method is independent of tissue shrinkage.

The total number of AVP, OXT neurons, and the total cell number (including neurons, glia, and endothelial cells) in the PVN were com- puted by multiplying the average numerical cell density with the volume of the population in question.

\section{Statistics}

Differences among the groups were tested in a two-tailed manner, using the Mann-Whitney U test statistics. Throughout this study, values were expressed as the mean \pm SEM. The critical level for statistical significance was taken to be $5 \%$.

\section{Results}

\section{Histology}

In thionine-stained sections, no gross qualitative difference was found between the PVN of PWS cases and controls (Fig. 1, A and B). After the five PWS cases had been matched with the five controls according to age and sex (Table 1), the PVN was quantitatively studied in thionine preparations (Table 2). The volume of the PVN in PWS patients appeared to be decreased by $28 \%(P=0.028)$. This was not so much due to a decreased rostro-caudal axis (9\%), but, rather, to the decreased size of the maximal area of the PVN (28\%; Table
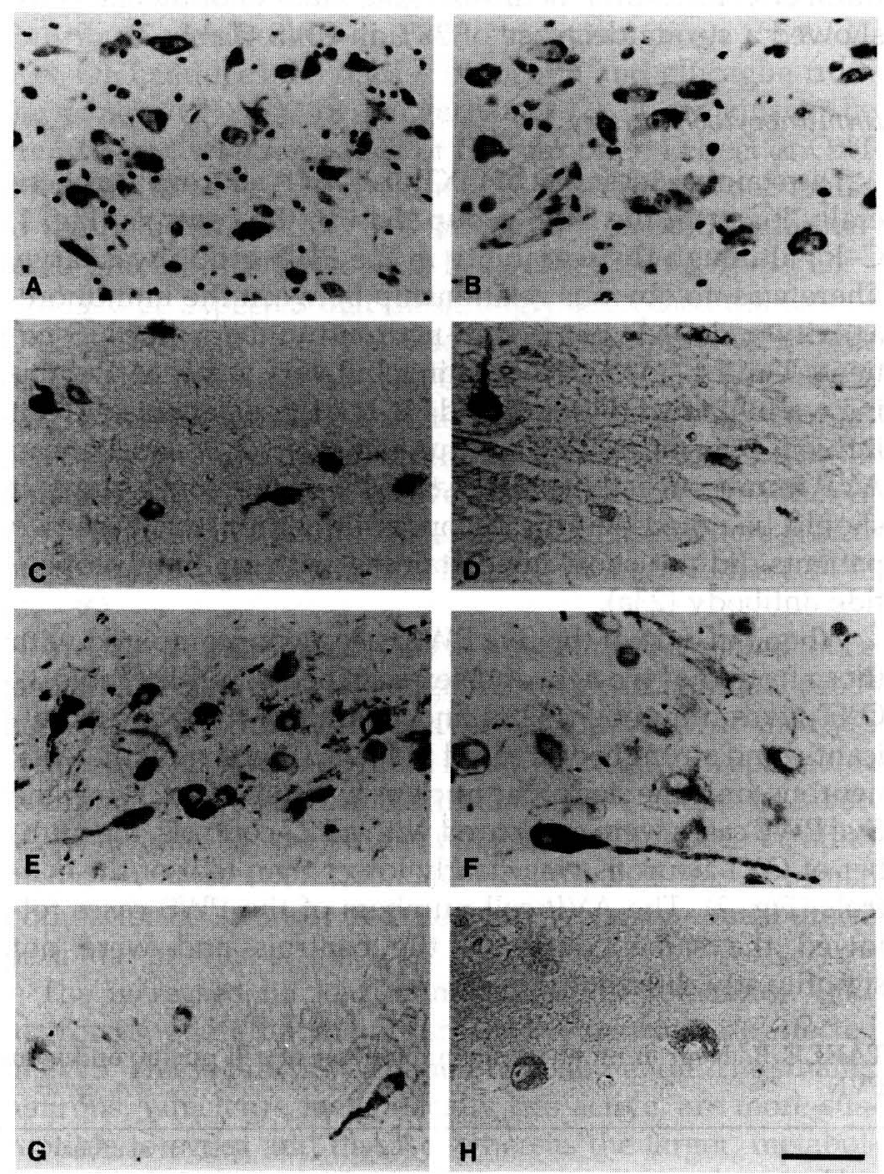

FIG. 1. In thionine-stained sections of the PVN, no qualitative differences were observed between controls (no. 81255; A) and PWS patients (no. 43830; B). The staining of OXT (C and D) and AVP (E and F) was generally lower in PWS patients (no. 43830; D and F) than in controls (no. 81255; $\mathrm{C}$ and $\mathrm{E}$ ). $\mathrm{G}$ and $\mathrm{H}$, Two PWS patients (no. 1 and 4) had intense and weak OXT staining (no. 93056; G) and only negligible AVP staining (no. 93056; H) in the PVN. The bar represents $50 \mu \mathrm{m}$. 
TABLE 2. $P V$ in thionine staining

\begin{tabular}{|c|c|c|c|c|c|}
\hline \multirow[b]{2}{*}{ Patient no. } & \multicolumn{5}{|c|}{ PVN (thionine) } \\
\hline & $\mathrm{Vol}\left(\mathrm{mm}^{3}\right)$ & Length (mm) & $\begin{array}{c}\text { Maximal area } \\
\left(\mathrm{mm}^{2}\right)\end{array}$ & $\begin{array}{l}\text { Cell density } \\
\left(\mathrm{mm}^{3} \times 10^{3}\right) \\
\end{array}$ & $\begin{array}{c}- \text { Total cell no. } \\
\left(\times 10^{3}\right)\end{array}$ \\
\hline $\begin{array}{c}\text { PWS } \\
1 \\
2 \\
3 \\
4 \\
5\end{array}$ & $\begin{array}{l}1.232 \\
2.974 \\
3.613 \\
4.071 \\
3.757\end{array}$ & $\begin{array}{l}1.20 \\
3.59 \\
5.16 \\
5.99 \\
2.40\end{array}$ & $\begin{array}{l}1.395 \\
1.329 \\
1.066 \\
0.866 \\
2.238\end{array}$ & $\begin{array}{l}203.5 \\
179.2 \\
200.2 \\
190.4 \\
196.1\end{array}$ & $\begin{array}{l}253 \\
533 \\
723 \\
775 \\
736\end{array}$ \\
\hline Mean \pm SEM & $3.13 \pm 0.51^{a}$ & $3.67 \pm 0.88$ & $1.379 \pm 0.235$ & $193.9 \pm 4.3$ & $604 \pm 97.35^{b}$ \\
\hline $\begin{array}{c}\text { Controls } \\
1 \\
2 \\
3 \\
4 \\
5\end{array}$ & $\begin{array}{l}4.403 \\
4.546 \\
5.035 \\
3.985 \\
3.822\end{array}$ & $\begin{array}{l}4.16 \\
3.60 \\
4.79 \\
4.14 \\
3.48\end{array}$ & $\begin{array}{l}1.347 \\
2.372 \\
1.695 \\
1.726 \\
2.392\end{array}$ & $\begin{array}{l}241.6 \\
245.6 \\
206.0 \\
196.3 \\
225.3\end{array}$ & $\begin{array}{c}1064 \\
1117 \\
1037 \\
782 \\
861\end{array}$ \\
\hline Mean $\pm \mathrm{SEM}$ & $4.36 \pm 0.21^{a}$ & $4.03 \pm 0.23$ & $1.906 \pm 0.205$ & $223.0 \pm 9.7$ & $972 \pm 64.12^{b}$ \\
\hline
\end{tabular}

f, Female; $m$, male.

${ }^{a} P=0.028$.

${ }^{b} P=0.009$.

2). Total cell density was $13 \%$ lower in PWS. The total cell numbers, including neurons, glia, and endothelial cells, showed a strong decrease of $38 \%$ in PWS (Table 2).

\section{Immunocytochemistry}

The staining intensity of OXT and AVP neurons was generally lower in the PWS group than in the controls (Fig. 1, C-F), although the variability in the PWS group was large. There was no obvious relationship between the immunoreactivity and OXT- or AVP-IR neuron numbers. In PWS patients 1 and 4, good OXT staining, but very weak AVP staining was obtained (Fig. 1, G and H), but these patients did not influence the mean AVP cell number (cases 2,3, and 5; mean AVP immunoreactivity, $1888 \pm 1505$ ) or our conclusions. It should be noted that the vasopressin neurons of these two patients did not show good staining with an antiglycopeptide antibody (23a).

When the data of the five PWS cases were compared with those from the five age- and sex-matched controls (Table 3 ), OXT neuron number $(42 \%)$ and volume $(54 \%)$ were significantly and strongly decreased in PWS. Concerning the AVP neurons, only the size of the nucleus was increased. When the five PWS cases were compared with all 27 controls, the number of OXT neurons was clearly lower than that of the controls (Fig. 2). The AVP cell numbers of the PWS cases followed the same course as the controls and were not significantly different (Fig. 2).
No significant difference was found for brain weight, postmortem tissue, or fixation time (see Table 1) when the five PWS cases were compared to the five sex-and age-matched controls. The OXT and AVP neuronal counts of the one PWS patient with a long fixation time (case 4 ) were not lower than those in the others, which shows that formalin fixation of more than $1 \mathrm{yr}$ did not affect the results.

\section{Discussion}

The main finding of the present paper is the $28 \%$ reduction in volume and the $41 \%$ reduction in total cell number of the thionine-stained PVN in PWS and the strong reduction (42\%) in the number of OXT neurons in the PVN of PWS patients. Comparison with the group of 26 controls did not give any indication that antimortem factors had influenced these results. In earlier studies, the number of OXT neurons was found to remain stable during the course of aging and in Alzheimer's disease (19). The stability in aging was confirmed in the present paper. Previously, a decrease in OXTexpressing cell numbers had only been observed in two disorders, i.e. Parkinson's disease ( $22 \%$ reduction) and autoimmunodeficiency syndrome (40\% reduction) $(24,25)$, both conditions in which typical PWS eating disorder symptoms, such as gross obesity and insatiable hunger, are not present. However, there is indeed an important difference between the present results in PWS and the findings in Par-

TABLE 3. Neuron number, mean diameter of cell nuclei, and volume of the population of OXT- and AVP-containing cells in the human PVN

\begin{tabular}{|c|c|c|c|c|c|c|}
\hline \multirow[b]{2}{*}{ Group } & \multicolumn{3}{|c|}{ OXT-IR neurons } & \multicolumn{3}{|c|}{ AVP-IR neurons } \\
\hline & $\begin{array}{c}\text { Neuron no. } \\
\left(\times 10^{3}\right)\end{array}$ & $\begin{array}{c}\text { Cell nuclear } \\
\text { diameter }(\mu \mathrm{m})\end{array}$ & $\operatorname{Vol}\left(\mathrm{mm}^{3}\right)$ & $\begin{array}{c}\text { Neuron no. } \\
\left(\times 10^{3}\right)\end{array}$ & $\begin{array}{c}\text { Cell nuclear } \\
\text { diameter }(\mu \mathrm{m})\end{array}$ & $\mathrm{Vol}\left(\mathrm{mm}^{3}\right)$ \\
\hline $\begin{array}{l}\text { Matched controls }(n=5) \\
\text { WS }(n=5)\end{array}$ & $\begin{array}{l}26.14 \pm 2.09 \\
15.25 \pm 2.09\end{array}$ & $\begin{array}{l}8.69 \pm 0.36 \\
9.48 \pm 0.28\end{array}$ & $\begin{array}{l}3.58 \pm 0.54 \\
1.64 \pm 0.19\end{array}$ & $\begin{array}{l}18.25 \pm 1.83 \\
17.18 \pm 1.895\end{array}$ & $\begin{aligned} 8.77 & \pm 0.53 \\
10.19 & \pm 0.16\end{aligned}$ & $\begin{array}{l}1.62 \pm 0.11 \\
1.60 \pm 0.25\end{array}$ \\
\hline Statistics $(P)^{a}$ & 0.016 & 0.172 & 0.028 & 0.465 & 0.016 & 0.754 \\
\hline
\end{tabular}

Values are given as the mean \pm SEM.

a Differences among the groups were tested in a two-tailed manner, using the Mann-Whitney U test. 
Prader-Willi Syndrome

FIG. 2. Number of OXT-expressing (left panel) and AVP-expressing (right panel) neurons in the PVN of 27 controls and 5 PWS patients. The values of the PWS patients are delineated by a minimum convex polygon. Note that the OXT neuron number of these patients is clearly lower than that of the controls (left panel), which is not the case for AVP (right panel).
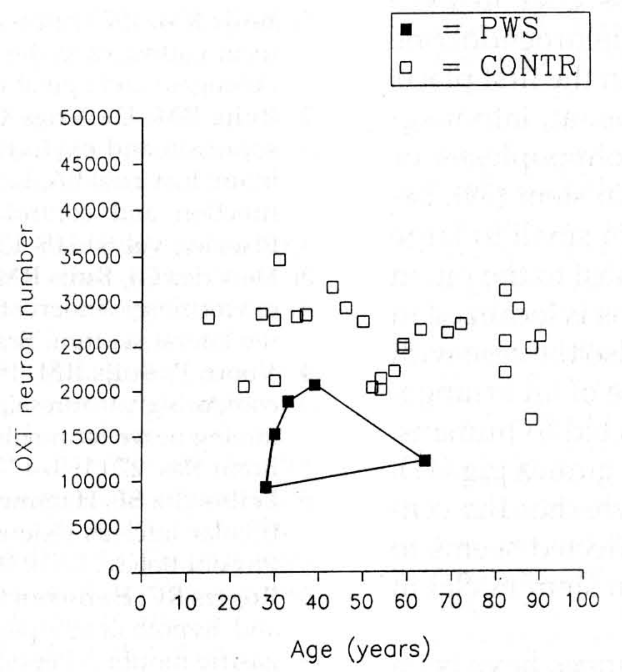

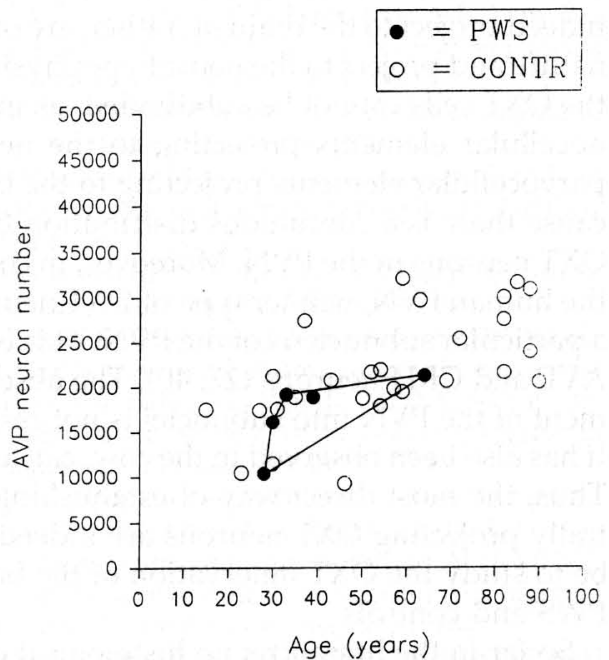

kinson's disease and AIDS. In the latter two conditions, the volume of the PVN containing OXT and AVP neurons does not alter, whereas in PWS, the volume of the OXT part of the PVN declines by $54 \%$. As the OXT and AVP cell populations only occupy some $50 \%$ of the entire PVN volume $(19,26,27)$, the PVN volume of the five PWS cases was compared to that of the five matched controls. Indeed, a $28 \%$ reduction was found in PWS patients, which shows that the PVN is anatomically affected in this syndrome.

Whether the neuronal reduction in PWS is restricted to the OXT neurons of the PVN, of course, remains to be seen. The unaltered AVP cell numbers in the PVN suggest, however, that this phenomenon is quite specific. With respect to the local specificity, it is of interest that Kremer (28) determined the number of neurons in the hypothalamic lateral tuberal nucleus of one PWS patient (no. 43830) and did not find a difference from controls. This nucleus is also considered to be involved in the regulation of feeding and metabolism (28).

After its release into the bloodstream in the neurohypophysis, OXT acts on peripheral organs as a neurohormone (for review, see Ref. 29), whereas OXT acts as a neurotransmitter or neuromodulator after its transport by nerve fibers and release from synapses in various brain areas (1-4). The lack of peripheral and central OXT effects due to the lower number of OXT neurons in the PVN of PWS patients may thus, in principle, both contribute to the symptomatology of this syndrome.

The gross obesity, due to insatiable hunger, which is so characteristic for PWS, may primarily be related to the observed decrease in OXT neurons in the PVN. It has been shown in animal experiments that OXT neurons projecting from the PVN to brain stem nuclei, such as the NTS and dorsal motor nucleus of the nervus vagus, are satiety neurons (see introduction). In addition to its central effects, the peripheral effects of OXT as a neurohormone may be presumed to be relevant to PWS. OXT acts on peripheral tissues as an insulin-like hormone. This neuropeptide stimulates glucose oxidation and lipogenesis and inhibits the lipogenic effects of catecholamines (30). However, in a study on six PWS pa- tients, no gross defects in lipid mobilization and transport were found (31), so these effects of OXT probably do not contribute significantly to PWS symptomatology. In addition, OXT induces the release of insulin and glucagon from the pancreatic islets of Langerhans (32). It remains to be investigated whether a lack of this peripheral effect of OXT due to the observed decrease in OXT cell number contributes to the diabetes mellitus and intolerance to orally administered glucose that have often been observed in PWS (33).

It is to be expected that the strongly decreased number of OXT neurons in the PVN also has implications for reproductive behavior (see above). On the other hand, in general, such behavior hardly comes to expression, as PWS is characterized by hypogonadism (more severe in males than in females), low sex hormone levels, testicular abnormalities in the germinal epithelium, and sporadic menses. There is only one report on fertility in two females thought to have PWS (34-36).

An early symptom that may at least partly be related to the lack of OXT neurons is the high frequency of perinatal problems that occur during the delivery of children with the PWS syndrome (11). The fetal brain is known to play an active role in timing the moment and stimulating the course of labor. More specifically, the course of labor is thought to be stimulated by fetal OXT (37). The finding that this neuronal population is strongly reduced in PWS may contribute to perinatal problems.

The increased nuclear diameters of the remaining OXT neurons suggest that mainly small OXT neurons are affected in PWS. This is probably a general phenomenon. The smaller neurons, which are metabolically less active, are more susceptible to aging and disease, whereas the larger, metabolically more active ones service these conditions better. This phenomenon has been paraphrased as "use it or lose it" (38). In rats, the parvocellular OXT neurons project to the brain stem (2-4). One might, thus, interpret our data as supporting the idea that the parvocellular neurons mainly projecting to the brain stem are affected in PWS.

However, a common problem in the interpretation of data 
on the human PVN is that it is not possible to determine with certainty if the neurons that do not express OXT in PWS indeed project to the brain or, rather, are of a neuroendocrine nature and project to the neurohypophysis. In the first place, the OXT cells cannot be subdivided, as in the rat, into magnocellular elements projecting to the neurohypophysis or parvocellular elements projecting to the brain stem (39), because there is a continuous distribution from small to large OXT neurons in the PVN. Moreover, in contrast to the rat, in the human PVN, neither type of OXT neurons is localized in a particular subnucleus of the PVN. This is also the case with AVP and CRH neurons $(27,40)$. The absence of an arrangement of the PVN into subnuclei is not restricted to humans. It has also been observed in the cow, cat, and guinea pig (41). Thus, the most direct way of establishing whether the centrally projecting OXT neurons are indeed affected seems to be to study the OXT innervation of the brain stem nuclei in PWS and controls.

So far in the literature, no histological changes have been reported in the six PWS patients whose hypothalami were investigated postmortem along the lines of conventional neuropathology $(33,42-45)$. In an earlier study, we found no expression of the neuroendocrine gene product $7 \mathrm{~B} 2$ in the supraoptic nucleus or PVN of two of the five PWS patients we examined (23a). It turned out that the brains of the same two PWS patients that lacked 7B2 expression (cases 1 and 4) hardly stained with antivasopressin, although all five PWS cases stained well with an antibody against the precursor of AVP (23a), which indicates a defect in the processing of this neuropeptide precursor.

The present paper revealed that the number of AVP neurons is normal, but the number of OXT neurons in the five PWS patients is low. This illustrates that by applying immunocytochemistry and morphometry, defects in hypothalamic nuclei may be detected that would remain unnoticed if conventional neuropathological means were used. Such techniques should now be applied to other nuclei and neuropeptide systems in PWS to obtain a better knowledge of the background of the mainly neuroendocrine symptomatology of this syndrome.

An interesting question in relation to the dual projection of OXT neurons, i.e. to the neurohypophysis and into the brain, is whether the strong reduction in OXT neurons found in PWS is also reflected by reduced OXT levels in peripheral blood. If so, it might be worthwhile to investigate whether OXT administration by nasal spray, a procedure that has been shown to elicit central effects in humans (46), inhibits or prevents the eating attacks of PWS patients.

\section{Acknowledgments}

We are indebted to Prof. C. B. Saper (44282), Dr. R. S. Williams (43830), Dr. M. E. J. Schipper (91-252), Dr. J. Xuereb (93-056), Dr. H. M. Evenhuis, and Dr. R. A. C. Roos (317-90) for their help in providing us with documented brain material of PWS patients. The control brain material was obtained from the Netherlands Brain Bank (coordinator: Dr. R. Ravid). We would also like to thank Mr. B. Fisser and Ms. A. A. Sluiter for their technical assistance, Mr. G. van der Meulen for his photographic work, and Ms. O. Pach for her secretarial support.

\section{References}

1. Buijs RM. 1978 Intra- and extrahypothalamic vasopressin and oxytocin pathways in the rat: pathways to the limbic system, medulla oblongata and spinal cord. Cell Tissue. 192:423-435.

2. Buijs RM, De Vries GJ, Van Leeuwen FW, Swaab DF. 1983 Vasopressin and oxytocin: distribution and putative functions in the brain. In: Cross BA, Leng GA, eds. The neurohypophysis: structure, function and control. Progress in brain research. Amsterdam: Elsevier; vol 60:115-122.

3. De Vries GJ, Buijs RM. 1983 The origin of the vasopressinergic and oxytocinergic innervation of the rat brain with special reference to the lateral septum. Brain Res. 273:307-317.

4. Voorn P, Buijs RM. 1983 An immuno-electronmicroscopical study comparing vasopressin, oxytocin, substance $\mathrm{P}$ and enkephalin containing nerve terminals in the nucleus of the solitary tract of the rat. Brain Res. 270:169-173.

5. Leibowitz SF, Hammer NJ, Chang K. 1981 Hypothalamic paraventricular nucleus lesions produce overeating and obesity in the rat. Physiol Behav. 27:1031-1040.

6. Rogers RC, Hermann GE. 1986 Oxytocin, oxytocin antagonist, TRH, and hypothalamic paraventricular nucleus stimulation effects on gastric motility. Peptides. 8:505-513.

7. Arletti R, Benelli A, Bertolini A. 1989 Influence of oxytocin on feeding behavior in the rat. Peptides. 10:89-93.

8. Benelli A, Bertolini A, Arletti R. 1991 Oxytocin-induced inhibition of feeding and drinking: no sexual dimorphism in rats. Neuropeptides. 20:57-62.

9. Olson BR, Drutarosky MD, Chow M-S, Hruby VJ, Stricker EM, Verbalis JG. 1991 Oxytocin and an oxytocin agonist administered centrally decrease food intake in rats. Peptides. 12:113-118.

10. Smeets DFCM, Hamel BCJ, Smeets HJM, et al. 1992 Prader-Willi syndrome and Angelman syndrome in cousins from a family with a translocation between chromosomes 6 and 15. N Engl J Med. 326:807-811.

11. Wharton RH, Bresman MJ. 1989 Neonatal respiratory depression and delay in diagnosis in Prader-Willi syndrome. Dev Med Child Neurol. 31:231-236.

12. Prader A, Labhart A, Willi H. 1956 Ein Syndrom von Adipositas, Kleinwuchs, Kryptorchismus und Oligophrenie nach Myotonieartigem Zustand in Neugeborenenalter. Schweiz Med Wochenschr. 86:1260-1261.

13. Argiolas A. 1992 Oxytocin stimulation of penile erection. Pharmacology, site, and mechanisms of action. In: Pedersen CA, Caldwell JD, Jirikowski GF, Insell TR, eds. Oxytocin in maternal, sexual, and social behaviors. New York: New York Academy of Sciences; 194203.

14. Arletti R, Benelli A, Bertolini A. 1992 Oxytocin involvement in male and female sexual behavior. In: Pedersen CA, Caldwell JD, Jirikowski GF, Insell TR, eds. Oxytocin in maternal, sexual, and social behaviors. New York: New York Academy of Sciences; $180-$ 193.

15. Carter CS. 1992 Oxytocin and sexual behavior. Neurosci Biobehav Rev. 16:131-144.

16. Hughes AM, Everitt BJ, Lightman SL, Todd K. 1987 Oxytocin in the central nervous system and sexual behaviour in male rats. Brain Res. 414:133-137.

17. Murphy MR, Seckl JR, Burton S, Checkley SA, Lightman SL. 1987 Changes in oxytocin and vasopressin secretion during sexual activity in men. J Clin Endocrinol Metabol. 65:738-741.

18. Pool CW, Madlener S, Diegenbach PC, Sluiter AA, Van der Sluis P. 1984 Quantification of antiserum reactivity in immunocytochemistry. Two new methods for measuring peroxidase activity on antigen-coupled beads incubated according to an immunocytoperoxidase method. J Histochem Cytochem. 32:921-928.

19. Wierda M, Goudsmit E, Van der Woude PF, et al. 1991 Oxytocin cell number in the human paraventricular nucleus remains constant with aging and in Alzheimer's disease. Neurobiol Aging. 12:511516.

20. Van Eden CG, Uylings HBM, Van Pelt J. 1984 Sex-difference and left-right asymmetries in the prefrontal cortex during postnatal development in the rat. Dev Brain Res. 12:146-153. 
21. Weibel ER. 1979 Stereological methods. London: Academic Press; vol 1:186-196.

22. Cruz-Orive LM. 1978 Particle shape size distributions: the general spheroid problem. II. Stochastic model and practical guide. J Microsc. 112:153-167.

23. Uylings HBM, Van Eden CG, Hofman MA. 1986 Morphometry of size/volume variables and comparison of their bivariate relations in the nervous system under different conditions. J Neurosci Methods. 18:19-37.

23a.Gabreëls BAThF, Swaab DF, Seidah NG, Van Duijnhoven HLP, Martens GJM, Van Leeuwen FW. 1994 Differential expression of the neuroendocrine polypeptide 7B2 in hypothalami of Prader-(Labhart)-Willi syndrome patients. Brain Res. 657:281-293.

24. Purba JS, Hofman MA, Swaab DF. 1994 Decreased number of oxytocin-immunoreactive neurons in the paraventricular nucleus of the hypothalamus in Parkinson's disease. Neurology. 44:84-89.

25. Purba JS, Hofman MA, Portegies P, Troost D, Swaab DF. 1993 Decreased number of oxytocin neurons in the paraventricular nucleus of the human hypothalamus in AIDS. Brain. 116:795-809.

26. Goudsmit E, Hofman MA, Fliers E, Swaab DF. 1990 The supraoptic and paraventricular nuclei of the hypothalamus in relation to sex, age and Alzheimer's disease. Neurobiol Aging. 11:529-536.

27. Van der Woude PF, Goudsmit E, Wierda M, et al. 1994 No vasopressin cell loss in the human paraventricular and supraoptic nucleus during aging and in Alzheimer's disease. Neurobiol Aging. In press.

28. Kremer HPH. 1992 The hypothalamic lateral tuberal nucleus: normal anatomy and changes in neurological diseases. In: Swaab DF, Hofman MA, Mirmiran M, Ravid R, Van Leeuwen FW, eds. The human hypothalamus in health and disease. Progress in Brain Research. Amsterdam: Elsevier; vol 93:249-261.

29. Swaab DF, Hofman MA, Lucassen PJ, Purba JS, Raadsheer FC, Van de Nes JAP. 1993 Functional neuroanatomy and neuropathology of the human hypothalamus. Anat Embryol. 187:317-330.

30. Lederis K, Goren HJ, Hollenberg MD. 1985 Oxytocin: an insulinlike hormone. In: Amico JA, Robinson AG, eds. Oxytocin: central and laboratory studies. Amsterdam: Elsevier; 284-302.

31. Bier DM, Kaplan SL, Havel RJ. 1977 The Prader-Willi syndrome. Regulation of fat transport. Diabetes. 26:874-881.

32. Stock S, Fastbom J, Björkstrand E, Ungerstedt U, Uvnäs-Moberg K. 1990 Effects of oxytocin on in vivo release of insulin and glucagon studied by microdialysis in the rat pancreas and autoradio- graphic evidence for $\left[{ }^{3} \mathrm{H}\right]$ oxytocin binding sites within the islets of Langerhans. Regul Pept. 30:1-13.

33. Bray GA, Dahms WT, Swerdloff RS, Fiser RH, Arkinson RL, Carrel RE. 1983 The Prader-Willi syndrome: a study of 40 patients and a review of the literature. Medicine. 62:59-80.

34. Butler MG. 1990 Prader-Willi syndrome: current understanding of cause and diagnosis. Am J Med Gen. 35:319-332.

35. Laxova R, Gilderdale S, Ridler MAC. 1973 An aetiological study of fifty-three female patients from a subnormality hospital and of their offspring. J Ment Defic Res. 17:193-225.

36. Wannarachue N, Ruvalcaba RHA, Kelley VC. 1975 Hypogonadism in Prader-Willi syndrome. Am J Mental Def. 79:592-603.

37. Swaab DF, Boer GJ, Boer K, Dogterom J, Van Leeuwen FW, Visser M. 1978 Fetal neuroendocrine mechanisms in development and parturition. In: Corner MA, Baker RE, Van de Poll NE, Swaab DF, Uylings HBM, eds. Maturation of the nervous system. Progress in Brain Research. Amsterdam: Elsevier; vol 48:277-289.

38. Swaab DF. 1991 Brain aging and Alzheimer's disease, "wear and tear" versus "use it or lose it." Neurobiol Aging. 12:317-324.

39. Swanson LW. 1987 The hypothalamus. In: Björklund A, Hökfelt T, Swanson LW, eds. Handbook of chemical neuroanatomy, integrated systems of the CNS, part 1. Amsterdam: Elsevier; 1-104.

40. Raadsheer FC, Sluiter AA, Ravid R, Tilders FJH, Swaab DF. 1993 Localization of corticotropin-releasing hormone (CRH) neurons in the paraventricular nucleus of the human hypothalamus; age-dependent colocalization with vasopressin. Brain Res. 615:50-62.

41. Sofroniew MV. 1985 Vasopressin, oxytocin and their related neurophysins. In: Björklund A, Hökfelt, T, eds. Handbook of chemical neuroanatomy, part 1. Amsterdam: Elsevier; vol 4:93-165.

42. Jenab M, Lade RI, Chiga M, Diehl AM. 1959 Cardiorespiratory syndrome of obesity in a child. Pediatrics. 24:23-30.

43. Reed WB, Ragsdale W, Curtis AC, Richards HJ. 1968 Acanthosis nigricans in association with various genodermatoses. Acta DermVenereol. 48:465-473.

44. Steiner H. 1968 Das Prader-Willi Syndrom. Virchows Arch [Pathol Anat]. 345:205-227.

45. Zellweger H, Schneider HJ. 1968 Syndrome of hypotonia-hypomentia-hypogonadism-obesity (HHHO) or Prader-Willi syndrome. Am J Dis Child. 115:588-598.

46. Ferrier BM, Kennett DJ, Devlin MC. 1980 Influence of oxytocin on human memory processes. Life Sci. 27:2311-2317. 